\title{
Sylvia P. Vance, The Memoirs of the Cardinal de Retz
}

\section{Antonella Amatuzzi}

\section{(2) OpenEdition}

\section{Journals}

\section{Edizione digitale}

URL: http://journals.openedition.org/studifrancesi/27543

DOI: 10.4000/studifrancesi.27543

ISSN: 2427-5856

\section{Editore}

Rosenberg \& Sellier

\section{Edizione cartacea}

Data di pubblicazione: 31 décembre 2006

Paginazione: 598

ISSN: 0039-2944

\section{Notizia bibliografica digitale}

Antonella Amatuzzi, «Sylvia P. Vance, The Memoirs of the Cardinal de Retz », Studi Francesi [Online], 150 (L | III) | 2006, online dal 30 novembre 2015, consultato il 08 novembre 2020. URL : http:// journals.openedition.org/studifrancesi/27543; DOI : https://doi.org/10.4000/studifrancesi.27543

Questo documento è stato generato automaticamente il 8 novembre 2020 .

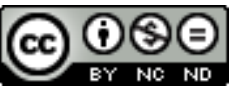

Studi Francesi è distribuita con Licenza Creative Commons Attribuzione - Non commerciale - Non opere derivate 4.0 Internazionale. 


\title{
Sylvia P. Vance, The Memoirs of the Cardinal de Retz
}

\author{
Antonella Amatuzzi
}

\section{NOTIZIA}

SYLVIA P. VANCE, The Memoirs of the Cardinal de Retz, Tübingen, Gunter Narr Verlag

(Biblio17, 158), 2005, pp. 343.

1 Questo lavoro intende analizzare come nelle Memorie di Retz, redatte venticinque anni dopo gli avvenimenti della Fronda, letteratura e storia si incrocino e come la ricostruzione a posteriori che il cardinale fa della storia attraverso i procedimenti narrativi adottati, sia analoga alla rappresentazione che egli vuole dare di sé.

2 In particolare, basandosi sugli studi di Genette riguardanti la relazione tra il tempo cronologico (serie degli avvenimenti, 'histoire') e lo spazio testuale ('récit'), l'a. individua nel testo quattro sezioni in cui il ritmo è rallentato e lo spazio narrativo dilatato: - l'episodio delle barricate (26-27 agosto 1648) studiato nei capitoli 1-2; - il blocco di Parigi (9-10-11 gennaio 1649) e gli eventi che portarono alla pace di Rueil (febbraio-marzo 1649) che sono trattati nei capitoli 3-4 e 5; - l'opposizione di Gondi a Condé (6 luglio-22 agosto 1651) di cui è questione nei capitoli 6 e 7.

3 Esaminando questi passaggi raccontati "al rallentatore" si osserva come metafore, metonimie, sineddoche e ironia sono usate per trattare sia temi storici sia questioni più strettamente personali lasciando così trasparire la grande complessità della scrittura di Retz.

4 Il libro è completato da due appendici (divisione delle Memorie secondo il ritmo narrativo ed un esempio di analisi effettuata su un passaggio) e da una bibliografia esaustiva. 